\title{
FELTY'S SYNDROME - A RARE DIAGNOSIS, BUT ONE THAT SHOULD NOT BE OVERLOOKED
}

\begin{abstract}
Andre Silva Franco ${ }^{1, \star}$, Elcio Koodiro Yoshida ${ }^{1}$, Isabele Parente de Brito Antonelli ${ }^{1}$, Guilherme Guimarães Moreira Balbi ${ }^{1}$, Janaina Baggio ${ }^{1}$, Heitor Furlan Giordano ${ }^{1}$, Henrique Ayres Mayrink Giardini ${ }^{1}$, Lissiane Karine Noronha Guedes ${ }^{1}$, Diogo Souza Domiciano ${ }^{1}$, Rosa Maria Rodrigues Pereira ${ }^{1}$
\end{abstract}

1. Hospital das Clínicas da Faculdade de Medicina da USP Universidade de São Paulo, São Paulo (SP), Brazil.

*Corresponding author: andre.franco@fm.usp.br

\section{BACKGROUND}

Felty's syndrome is a very uncommon extra-articular manifestation of rheumatoid arthritis (RA) characterized by the triad: RA, neutropenia and splenomegaly. It is a severe entity complicating long-standing disease and it is estimated to occur in 1 to $3 \%$ of RA patients. Evidence shows that global incidence of FS has decreased, probably due to widespread use of immunosuppressive drugs in RA, especially immunobiological agents.

\section{CASE REPORT}

A 74-year-old woman with a 40-year history of seropositive RA (rheumatoid factor titer higher than $1000 \mathrm{IU} / \mathrm{mL}$ and anti-citrullinated peptide antibodies of $94 \mathrm{IU} / \mathrm{mL}$ ) with severe joint deformities, previous atlantoaxial subluxation, rheumatoid nodules, and prior leflunomide-induced polyneuropathy was admitted for evaluation of fatigue, severe functional decline, weight loss of $15 \mathrm{~kg}$ during the last year and lower limb ulcers. Her RA had been in remission for over 5 years, and she was using low doses of methotrexate (7.5 mg/week). Physical examination demonstrated severe joint deformities without signs of synovitis or pain, mild splenomegaly confirmed by imaging and no lymphadenomegaly. Upon admission to our service, an intensive investigation of neoplastic and chronic infectious diseases was carried out. Laboratory workup showed increased inflammatory markers (C-reactive protein $79.6 \mathrm{mg} / \mathrm{L}$; erythrocyte sedimentation rate $96 \mathrm{~mm} / 1 \mathrm{st}$ hour), hypoalbuminemia (3 g/dL) and pancytopenia - hemoglobin $9.9 \mathrm{~g} / \mathrm{dL}$, 1,530 leukocytes $/ \mathrm{mm}^{3}, 860$ granulocytes $/ \mathrm{mm}^{3}, 420$ lymphocytes $/ \mathrm{mm}^{3}$, and 124,000 platelets $/ \mathrm{mm}^{3}$. Articular ultrasound showed no disease activity without power doppler signal. Cancer screening, including upper and lower digestive endoscopy and head-to-pelvis computerized tomography scan, did not evidence tumors. Infectious serology tests (hepatitis A, B and C, leishmaniasis, cytomegalovirus, HIV, Epstein-Barr, syphilis, toxoplasmosis) also resulted negative. Due to neutropenia associated with RA, lymphoma or large granular lymphocytic leukemia were considered as alternative diagnoses, but the absence of monoclonal expansion of lymphocytes on peripheral blood immunophenotyping ruled them out. Thus, a diagnosis of Felty's syndrome was made and she was treated with prednisone $1 \mathrm{mg} / \mathrm{kg} /$ day, and sulfasalazine $1 \mathrm{~g} /$ day along with methotrexate $15 \mathrm{mg} /$ week. There was a progressive improvement of symptoms and laboratory markers (C-reactive protein $5.6 \mathrm{mg} / \mathrm{L}$; erythrocyte sedimentation rate $8 \mathrm{~mm} / 1 \mathrm{st}$ hour), with functional and weight recovery.

\section{CONCLUSION}

Although rare, Felty's syndrome should be considered for patients with long-term RA, despite the absence of arthritis. Neutropenia, splenomegaly, and symptoms due to increased inflammatory activity may be observed. Chronic infectious diseases and neoplasia should be ruled out in these patients before starting therapy.

\section{KEYWORDS}

Rheumatoid arthritis, Felty's syndrome, Extra-articular manifestation. 